\title{
Os saberes e a formação profissional em lazer: uma análise no campo das políticas públicas
}

\author{
Bruno Ocelli Ungheri ${ }^{\mathrm{I}, \text { II }}$ \\ Hélder Ferreira Isayama ${ }^{\text {III, IV }}$
}

http://dx.doi.org/10.24109/2176-6681.rbep.98i249.2842

Universidade Federal de Minas Gerais (UFMG), Belo Horizonte, Minas Gerais, Brasil. E-mail: <bruno.ocelli@ yahoo.com.br >; <http://orcid. org/0000-0003-4827-5874>.

II Mestre em Estudos do Lazer pela Universidade Federal de Minas Gerais (UFMG), Belo Horizonte, Minas Gerais, Brasil.

III Universidade Federal de Minas Gerais (UFMG), Belo Horizonte, Minas Gerais, Brasil. E-mail: <isayamahf@ hotmail.com>; <http://orcid. org/0000-0002-4442-5356>.

IV Doutor em Educação Física pela Universidade Estadual de Campinas (Unicamp) Campinas, São Paulo, Brasil.

\section{Resumo}

Este estudo objetiva identificar e analisar os saberes necessários para atuação de profissionais em elaboração, implementação, desenvolvimento e avaliação de políticas públicas de esporte e lazer. Para a realização da pesquisa de campo, optou-se pela análise do trabalho desenvolvido na Secretaria Municipal de Esporte e Lazer de Belo Horizonte, órgão responsável pela coordenação das políticas públicas de esporte e lazer no município. Utilizou-se uma abordagem qualitativa que envolveu pesquisa bibliográfica e de campo, tendo esta ocorrido em duas etapas distintas, sendo a primeira uma imersão no campo de estudo, complementada pela realização de nove entrevistas semiestruturadas com oito analistas de políticas públicas e um gestor. Identificou-se que as dificuldades e as problemáticas vivenciadas em campo permitem ao profissional identificar as lacunas de sua formação, que, no contexto analisado, se relacionam, principalmente, aos saberes ligados à gestão. Por fim, notou-se que os saberes mobilizados para atuação nas políticas públicas de esporte e lazer são compostos por quatro eixos que compreendem: saberes específicos da área de atuação (esporte e lazer); conhecimentos sobre política e políticas públicas; domínio de conteúdos relacionados à gestão; e conhecimentos sobre o contexto e os sujeitos da ação.

Palavras-chave: construção de saberes; formação profissional; políticas públicas; esporte; lazer. 


\section{Abstract \\ The knowledge and professional training in leisure: an analysis performed in the field of public policy}

This study aims at identifying and analyzing the know-how needed to professionally engage in the making, implementation, development, and evaluation of leisure and sports public policies. In order to conduct field research, the work done by Secretaria Municipal de Esporte e Lazer from Belo Horizonte was analyzed, an entity responsible for local sport and leisure public policies. A qualitative approach using both bibliographic and field research was employed. The field research was conducted in two different stages, the first one being an immersion in the field of study; the second, a nine semi-structured interviews with eight public policy analyst and one manager. It was verified that difficulties and problems experienced in the field only aid professionals to identify gaps on their training that, in the analyzed context, were primarily related to issues of management. Ultimately, it was observed that the handling of sports and leisure public policies encompasses four pillars, namely: specific know-how on the area (sports and leisure); knowledge of politics and public policies; grasp on management; and knowledge of the context and the subjects involved in the policies.

Keywords: construction of knowledge; professional qualification; public policy; sport; leisure.

\section{Introdução}

No Brasil, o lazer foi inserido como direito social no artigo $6^{\circ}$ da Constituição Federal de 1988 (Brasil, 1988), sendo também destacado no artigo 217, o qual evidencia o papel do Estado no fomento às práticas de esporte e lazer. Sublinha-se o comprometimento do Estado com a destinação de recursos públicos para a promoção prioritária do desporto educacional e, em casos específicos, para o desporto de alto rendimento. O parágrafo $3^{\circ}$ enfatiza, ainda, o papel do poder público de incentivar o lazer como forma de promoção social. A inclusão do esporte e do lazer como direitos sociais foram avanços, pois representaram a inserção dos temas na agenda política.

Marcellino (2001) afirma que o lazer não é um oásis a que todos têm acesso, dadas as inúmeras barreiras econômicas e sociais que justificam sua inserção na agenda de elaboração e implementação de políticas públicas. Como o acesso quantitativo e, principalmente, qualitativo das pessoas ao lazer é condicionado a questões sociais, a inexistência de ações públicas pode excluir parte significativa da população brasileira, a menos que esta 
tenha condições de pagar pelas oportunidades oferecidas pelo mercado do entretenimento.

Menicucci (2008) acrescenta que as políticas públicas de esporte e lazer são iniciativas relativamente recentes no Brasil e adquirem visibilidade a partir da Constituição de 1988. Assim, o campo conceitual relacionado ao tema ainda é frouxo uma vez que há diferentes definições para os conceitos, associados a variados conteúdos culturais, o que dificulta a definição do escopo das políticas voltadas para a garantia do esporte e do lazer. Nesse sentido, a garantia desses direitos sociais não passa pela simples inclusão das palavras esporte e lazer em textos políticos, mas pela concepção de suas possibilidades na formação de uma sociedade justa e reflexiva.

Para que as políticas públicas de esporte e lazer sejam desenvolvidas, Vaz (2001, p. 12) afirma que "é necessária a vontade estatal de intervir". Apesar da existência de diversas ações, não se pode exigir da administração pública que fomente um número definido de projetos vinculados ao esporte, devido ao fato de a própria Constituição Federal citar o esporte como direito individual, mas não como direito obrigatório. É, portanto, função do Estado proporcionar meios para o desenvolvimento de práticas esportivas e de lazer na sociedade, porém o indivíduo faz uso desses meios apenas de acordo com sua vontade. Assim, as políticas de esporte e lazer deveriam ir além das ações voltadas especificamente a seu atendimento. Deveriam estar presentes nas políticas de outras áreas, como educação, saúde, segurança e assistência social, o que contribuiria para a superação do olhar limitado de que o sujeito só as utiliza de acordo com a sua vontade.

Alcançar esse patamar requer o amadurecimento das relações políticoinstitucionais estabelecidas no Brasil. Como observam Suassuna e Almeida (2005), a falta de planejamento tem impedido que a definição de políticas alcance caráter intersetorial, uma vez que a preparação de um plano de ação conferiria legitimidade a esse processo de intersetorialidade. Nessa direção, os autores ressaltam que o caráter setorial do planejamento adotado pelo governo nacional nas políticas públicas para o esporte e o lazer pode resultar em um conjunto de experiências não aprofundadas, devido ao caráter parcial assumido pela política.

As políticas de garantia ao incentivo do lazer devem estar voltadas para as premissas normativas da política pública. Com isso, evidencia-se a necessidade de democratizar o acesso a oportunidades de lazer e esporte, de promover inclusão social e de o Estado se obrigar a garantir a possibilidade de acesso a bens e serviços não unicamente pela via do mercado, quando esses assumem status de direito (Menicucci, 2008).

Isayama e Linhales (2008) apontam criticamente o caráter compensatório recorrente nas políticas públicas de lazer, que guarda estreita relação com as tensões e contradições do mundo do trabalho. Assim, o esporte e o lazer são considerados tempo de prevenção e cura do cansaço decorrente das ocupações profissionais ou práticas disciplinadoras capazes de guiar as pessoas à lógica da sociedade de massas. 
Tal caráter deve ser questionado e superado em relação à institucionalização do esporte e do lazer mediante políticas públicas. Como aponta Gomes (2014), a concepção de lazer como oposição ao trabalho não tem conseguido problematizar as complexidades e as dinâmicas que marcam as diferentes dimensões da vida coletiva no século 21. Desse modo, é imprescindível reconhecer o lazer como prática social cotidiana, situada em distintos tempos e espaços sociais, que, por esse motivo, integra diferentes culturas.

Portanto, existem algumas dificuldades para a incorporação do esporte e do lazer em ações e promoções públicas que visem à garantia de direitos sociais. Entre essas dificuldades, destaque-se o caráter parcial e limitado atribuído ao conteúdo dessas ações, o que pode ser considerado um empecilho, uma vez que essas são restringidas a aspectos como tempo para descanso e divertimento. Além disso, aspectos materiais como a destinação de espaços e a liberação de recursos, aliados à ressonância diferenciada dessa temática, quando comparada a outras, constituem problemáticas relacionadas ao esporte e ao lazer enquanto ferramentas de ascensão social e direitos que devem ser garantidos.

Marcellino (1996) afirma que essas dificuldades fazem com que a formulação de políticas de esporte e lazer se resuma a calendário de eventos ou a pacotes de atividades formuladas em gabinetes técnicos. Com isso, não são contempladas as possibilidades de transformação social que seus conteúdos podem viabilizar. Tendo em vista que essa configuração ainda se apresenta na realidade brasileira, pensar a atuação profissional nessas políticas passa pela construção de uma visão capaz de elevá-las ao patamar de atividades-fim, e não mais de atividades-meio.

A tendência de se limitar o lazer a atividades relacionadas ao esporte, à arte e à recreação reflete nas diferenciadas nomenclaturas dadas às repartições públicas e políticas que tratam o tema. Assim, durante o texto, utilizaremos os termos esporte e lazer tanto por entender ser esse o enfoque adotado por muitos órgãos públicos responsáveis por sua garantia, quanto por, sob perspectiva histórica, o tratamento desses elementos de forma conjunta ser identificado desde o século passado.

A partir de uma abordagem que considere os aspectos teóricos e conceituais relacionados ao esporte e ao lazer, torna-se importante direcionar o olhar aos profissionais e às ações públicas destinadas à sua garantia. Para Marcellino (2001), as áreas de educação física e turismo devem adotar esse enfoque como prioritário, bem como devem buscar, constantemente, a superação de uma visão centrada no fazer. Entendemos que há avanço quanto à formação de profissionais para atuação na área, mas concordamos com o autor quando afirma que essa abordagem não deve ser deixada de lado, evitando-se retrocessos.

Destacamos, então, a relevância de estudos que tratem especificamente da inclusão do esporte e do lazer em políticas públicas setoriais articuladas, uma vez que esses estudos podem orientar, com os conhecimentos necessários, os profissionais atuantes em elaboração, implementação, monitoramento e avaliação das políticas públicas nessa área. 
No que diz respeito às equipes de profissionais dos programas de esporte e lazer, o estudo de Linhales et al. (2008) identificou os seguintes problemas: (i) a composição dos quadros ocorre sem padrões e normas; (ii) a mensuração da competência profissional para a realização das ações considera, prioritariamente, a inserção dos profissionais no mundo esportivo.

Esse é um fato que aponta para duas problemáticas: a primeira relaciona-se à desvinculação de uma formação profissional para atuação na área, uma vez que o passado esportivo é tido como suficiente para uma intervenção aceitável; a segunda, que remete à reflexão anterior, é o reforço dado à limitação do lazer ao esporte.

Diante disso, é relevante compreender as atitudes que envolvem o esporte e o lazer, os valores que os propiciam, a consideração de seus aspectos educativos, suas possibilidades como instrumento de mobilização e participação cultural, além das barreiras socioculturais verificadas para seu efetivo exercício. E preciso, porém, que se tome o cuidado de vincular formação e desenvolvimento de pessoal às políticas públicas na área, pois, para a implementação de políticas públicas alicerçadas em valores de participação popular e de contribuição, no plano cultural, para o exercício da cidadania, é fundamental a formação e o desenvolvimento de quadros para atuação. Esse aspecto deve ser pensado na perspectiva da reversão de expectativas da própria população, viciada pelos valores da indústria cultural em amplos setores, a fim de qualificar a demanda por serviços públicos para determinadas parcelas populacionais (Marcellino et. al., 2007).

De qualquer maneira, diferentes programas e projetos têm sido desenvolvidos e, com isso, ampliam as possibilidades de intervenção de profissionais de diferentes áreas, inclusive nos campos da educação física, educação e turismo. Diante do exposto, o objetivo deste trabalho foi identificar e analisar os saberes necessários para atuação de profissionais em elaboração, implementação, monitoramento e avaliação de políticas públicas de esporte e lazer.

\section{Metodologia}

Visando analisar os saberes selecionados para a atuação profissional em políticas públicas de esporte e lazer, foi escolhida a abordagem qualitativa, combinada com pesquisa bibliográfica e de campo. Para realização da pesquisa de campo, optamos pela análise do trabalho desenvolvido na Secretaria Municipal de Esporte e Lazer de Belo Horizonte (SMEL), órgão responsável pela coordenação das políticas públicas de esporte e lazer no município.

A pesquisa de campo se deu em dois momentos distintos: a imersão e a realização de entrevistas. Inicialmente, fomos a campo para compreender o funcionamento administrativo, técnico e organizacional da SMEL, bem como para conhecer os sujeitos da pesquisa e as relações que se estabelecem em seu cotidiano laboral. Foram realizadas oito visitas à Secretaria, quando foi possível acessar documentos, conhecer seu quadro de colaboradores, os projetos desenvolvidos, as dinâmicas e as relações estabelecidas entre as áreas. 
Como critério de seleção, decidimos pela indicação de um analista de cada programa ou área estruturadora da SMEL, visando a conferir visibilidade às diferentes realidades vivenciadas. Com isso, fizeram parte da pesquisa de campo oito analistas de políticas públicas de esporte e lazer.

Entrevistamos um analista de cada um(a) dos(as) seguintes programas/ áreas: Programa Caminhar, Programa Esporte Esperança, Programa Superar, Programa Esporte e Lazer na Cidade (Pelc), Programa Vida Ativa, Centro de Memória do Esporte e Lazer (CBEL), Gerência de Eventos e Gerência de Esportes de Alto Rendimento. Além disso, um gestor - não entendido como profissional de carreira - foi entrevistado no intuito de trazer para o contex to de análise outro olhar acerca das políticas públicas de esporte e lazer no município. Os entrevistados foram informados sobre os objetivos da pesquisa e previamente consultados sobre a disponibilidade para a sua realização. Após confirmação das entrevistas, os sujeitos assinaram o Termo de Consentimento Livre e Esclarecido.

A análise dos dados coletados das entrevistas se deu por intermédio da análise de conteúdo proposta por Bardin (1977), que envolve um conjunto de técnicas de análise das comunicações, cujo objetivo é, mediante procedimentos sistemáticos de descrição do conteúdo das mensagens, obter indicadores que permitam a inferência de conhecimentos relativos às condições de produção e recepção dessas mensagens. Desse modo, os dados brutos são compilados e, posteriormente, sistematizados em categorias de análise que potencializam o apontamento de possíveis respostas às questões norteadoras da pesquisa.

\section{A formação dos sujeitos da pesquisa}

A formação acadêmica não pode ser entendida como único caminho para a constituição de profissionais. Assumi-la como tal nos faria desconsiderar a influência das relações e experiências vividas pelas pessoas nas relações cotidianas, conforme destacado nos trabalhos de Tardif (2000, 2008).

Todos os analistas entrevistados possuíam graduação em Educação Física e vivências na área, uma vez que já atuavam, em média, havia 21 anos no mercado (o tempo da maior e da menor experiência era de 30 e de 12 anos). Dois dos entrevistados possuíam uma segunda formação acadêmica, motivada pelo interesse pessoal em ampliar os conteúdos necessários para sua atuação profissional (Turismo e Psicologia). Assim, complementaram sua formação inicial por meio da busca de conhecimentos relacionados à sua intervenção na SMEL.

Observamos que todos os profissionais complementaram sua formação acadêmica com cursos em pós-graduação lato sensu e stricto sensu. Identificamos, ainda, que a busca por qualificação não ocorreu especificamente pela exigência do mercado, mas pela intenção de cada indivíduo em qualificar sua intervenção profissional. 
Silva e Silva (2012, p. 70) afirmam que "a educação física tem como especificidade os conteúdos físico-esportivos do lazer". Esse pode ser um ponto de partida para a intervenção, de modo que os profissionais de educação física não devem limitar sua atuação no lazer às manifestações físico-esportivas, mas compreender essa atuação como campo multidisciplinar, capaz de levar os indivíduos ao desenvolvimento social e pessoal.

As falas dos sujeitos exemplificaram essa demanda por expandir sua atuação, uma vez que foi relatada a busca por conhecimentos complementares em diversas áreas, não apenas na educação física. O sujeito 4 (S4), por exemplo, buscou aprofundar conhecimentos nos conteúdos de gestão e políticas públicas. Por outro lado, o sujeito 5 (S5) procurou uma segunda graduação, em Turismo, para compreender as relações que se estabelecem na cidade e como se dá a organização desse espaço.

Esse contexto aponta para o caráter multidisciplinar e interdisciplinar referente às políticas públicas de esporte e lazer, uma vez que os profissionais complementaram sua formação profissional por meio da busca de conhecimentos em áreas distintas à formação acadêmica inicial. Portanto, as informações que emergem da pesquisa vão ao encontro das reflexões de autores do lazer (Isayama et al., 2011; Stoppa et al., 2011), que apontam para a abrangência do tema e, consequentemente, para a necessidade de pensá-lo sob um viés integrador de diferentes áreas do conhecimento.

Um fato importante para se compreender esse processo também pode ser explicado pelas falas dos sujeitos, uma vez que foi recorrente nas entrevistas a constatação de que sua formação inicial teve limites quanto aos conhecimentos relacionados às políticas públicas de esporte e lazer:

Fui conhecer o serviço público depois de trabalhar aqui por dois ou três anos. Minha formação não teve nada sobre política, entrei na Secretaria sem saber o que viria pela frente. Mas hoje me considero apto a trabalhar aqui, até porque "corri atrás" do prejuízo e procurei me atualizar (S6).

Nessa direção, os sujeitos da pesquisa apontaram limites dos cursos de graduação no fornecimento de subsídios teórico-práticos para sua atuação como analistas de políticas públicas de esporte e lazer. Em geral, citaram a presença de algumas disciplinas como complementares à preparação para essa atuação, como a fisiologia do exercício, sociologia da educação e iniciação esportiva, com as quais a apropriação de conhecimentos se deu de forma mais acentuada durante sua atuação, por meio de processos formais ou não, que levam ao amadurecimento profissional.

É necessário ter em mente que abordar criticamente os processos formais não implica assumir que esses processos têm mais importância que as demais formas de absorção e utilização do conhecimento. Para Schön (2007), a formação profissional deve interagir com a teoria e a prática, por meio de um ensino reflexivo baseado no processo de "reflexão na ação".

É possível inferir que, durante sua atuação profissional, os sujeitos da pesquisa perceberam a necessidade de aprimorar conhecimentos para superar os desafios enfrentados cotidianamente, como evidencia o trecho transcrito: 
Cada um se virou por aqui e buscou um mestrado ou uma especialização. Eu mesmo fiz duas especializações porque tive a iniciativa de buscá-las, pagar a mensalidade e fazer os cursos. Se dependesse do serviço público eu realmente ficaria aqui de braços cruzados (S9).

Concordamos com Isayama (2002) quando afirma que existem limites na discussão dos conhecimentos sobre a formação em educação física no Brasil. $\mathrm{O}$ autor constata que esse quadro exige uma reformulação das propostas curriculares, para que se possa haver uma discussão de qualidade sobre o esporte e o lazer dentro dos cursos de formação profissional. Particularmente, acreditamos ser esse o tema central na discussão das políticas públicas de esporte e lazer. É preciso superar os modelos estabelecidos até então e construir outras propostas de formação para os profissionais que atuam e irão atuar no campo.

A formação dos sujeitos não deve se basear exclusivamente em currículos centralizados em disciplinas acadêmicas, uma vez que os conteúdos e conhecimentos necessários para atuação em campo podem emergir de diferentes formas. Nessa perspectiva, o fato de a formação inicial dos sujeitos não ter abordado disciplinas específicas sobre política e políticas públicas é significativo para a ausência de uma abordagem consolidada acerca desse aspecto na área de esporte e lazer, mas não pode justificar isoladamente essa formação deficitária.

Sendo assim, o currículo pode ser considerado um facilitador das ações docentes, mas não deve se apoiar na ideia de conteúdos essenciais ou na noção de construção livre, sem parâmetros ou diretrizes. Bagrichevsky (2007) acrescenta que a necessidade de formação superior em determinadas áreas evidencia a exigência de uma formação complexa e elaborada para atuação. Para o autor, esse processo confere maior aporte técnicocientífico e mais elevado nível de reflexão crítica aos futuros profissionais, possibilitando-lhes a aquisição de embasamento para o cumprimento socialmente satisfatório de suas atribuições. Nessa perspectiva, destaca que tal percurso, por si só, não prepara os sujeitos para a vida profissional, tendo que se pensar uma formação ampliada, que valorize as trocas de conhecimentos em diferentes níveis.

Tendo em vista que, em média, os profissionais entrevistados concluíram sua graduação havia 21 anos, é importante avaliar o estado em que se encontrava a formação profissional para atuação nas políticas públicas de esporte e lazer. Isayama et al. (2011) afirmam que os processos de formação profissional nos campos do esporte e lazer vêm ganhando espaço nos meios acadêmicos, bem como no âmbito das políticas públicas vigentes. Os autores entendem como fundamental a formação de profissionais para atuar como dinamizadores das vivências oferecidas nas propostas do setor público.

Entendemos ser relevante uma reflexão que, de certo modo, pode se concretizar numa provocação: qual a interação possível para se estabelecerem vínculos entre a formação profissional em políticas públicas de esporte e lazer e sua efetivação junto aos programas e ações do poder público? 
O fato de a formação profissional para atuação nas políticas de esporte e lazer se constituir num campo em crescimento não é suficiente para afirmar que os profissionais formados recentemente tenham melhor qualificação do que aqueles que já atuam. Por outro lado, observamos que pouco se fez para complementar ou aumentar os quadros de profissionais no contexto analisado, uma vez que, após a última chamada dos profissionais, houve a realização de apenas um concurso público.

Desse modo, não houve inclusão significativa de novos profissionais que pudessem atuar no campo e interagir com outros colegas com mais tempo de experiência. Certamente, não se pode desconsiderar a formação continuada dos profissionais analisados, mas acreditamos que a inserção de novos profissionais, com, obviamente, outras formações, seja uma questão importante a se pensar em futuras investigações, tendo em vista que a interação entre diferentes perfis profissionais poderia promover intercâmbio de conhecimento e qualificar as ações desenvolvidas pela SMEL.

Esse fator nos remete à ideia de interdisciplinaridade, uma vez que a atuação de profissionais de diferentes campos do conhecimento pode lançar diferentes olhares sobre determinado tema. Trazendo o esporte e o lazer para o cenário, é possível qualificar suas formas de intervenção na sociedade, na medida em que se permite a atuação de diferentes áreas, não apenas da educação física.

Linhales et al. (2008) exemplificam a necessidade de abordagem interdisciplinar ao constatar que a presença do esporte e do lazer vai além das ações públicas destinadas à sua promoção como política isolada e está vinculada às políticas de saúde, educação, segurança e previdência social. A construção de propostas nessas áreas demanda a atuação de sujeitos com diferentes tipos de formação, evidenciando o trabalho interdisciplinar.

Trata-se, portanto, de repensar a formação dos profissionais e a forma como as políticas são gerenciadas. Nessa perspectiva, Pinto et al. (2011) apontam que é importante capacitar equipes multidisciplinares para a gestão do lazer, exigindo-se formação especializada. Com isso, é possível formar gestores públicos capazes de promover a democracia e os interesses ligados às práticas de lazer, valorizando sua ação transversal nas políticas sociais. Refletir criticamente sobre a formação profissional e valorizar a abordagem multidisciplinar na área do lazer e do esporte segue em direção à solução dos problemas enfrentados pelas políticas de esporte e lazer, mas é preciso ter em mente que se trata apenas de possibilidades.

Outro ponto que emergiu da fala de sete dos entrevistados se refere ao passado esportivo como elemento de interferência em sua vinculação às políticas de esporte e lazer. É importante destacar que seis analistas citaram esse elemento como relevante para a escolha da educação física enquanto área de atuação:

Meu envolvimento com o esporte, principalmente com o voleibol, foi essencial para eu escolher a educação física como profissão (S2).

Fiz atletismo muitos anos e sempre estive perto do esporte. Então, como estava confuso quanto à profissão que queria seguir, resolvi fazer o vestibular para educação física, passei e estou aqui até hoje (S5). 
O passado esportivo como atleta dos gestores precisa ser analisado, pois pode estar ligado à promoção de popularidade do setor público perante a sociedade ou à promoção do alto rendimento esportivo como modelo de ascensão social e "caminho natural" para a ocupação de cargos públicos, ainda que o sujeito que possui o esporte em sua trajetória conheça as particularidades deste e possa contribuir para o desenvolvimento de ações nesse âmbito. Em outra direção, um dos entrevistados menciona como referência a formação esportiva que teve durante o ensino fundamental. Nesse caso, os professores de educação física também podem ser pensados como influência nas escolhas e na atuação profissional dos sujeitos:

Teve meu professor de educação física no colégio, que foi em quem eu me espelhei por identificar com sua perspectiva. Minha escola era uma referência de educação física na época, aí eu fiz atletismo e joguei vôlei - mesmo sendo baixo - e foi até isso que me motivou a trabalhar com pessoas com deficiência (S8).

Daolio (1996) destaca que o professor de educação física leva seu aluno ao reconhecimento de valores, muitas vezes inconscientes, que dão suporte e sentido às escolhas futuras do indivíduo e à sua forma de atuação no mundo. Diante dessa perspectiva, a fala de S8 é notável e aprofunda a questão exposta, apontando reflexos em sua vida pessoal e profissional.

Nessa perspectiva, Kogut e Martins (2009) afirmam que a formação profissional dos sujeitos tem reflexos dos primeiros anos escolares, uma vez que a escolha pela profissão é definida por perspectivas de trabalho e por muitas variantes, entre as quais o gosto pela carreira, a influência de familiares, de amigos ou da mídia. Para as autoras, ao chegarem na universidade, os alunos já têm algum conhecimento sobre o que é a profissão, o que o profissional faz, como e onde o ofício pode ser desenvolvido. Muitos desses conhecimentos foram construídos com base em informações recebidas em diversas situações ou experiências vividas no contato com a profissão - no caso da educação física, esse processo pode ser exemplificado pelas aulas escolares, por experiências competitivas ou pelas referências absorvidas com os professores.

Linhales et al. (2008) analisaram o perfil dos gestores municipais de esporte e lazer da Região Metropolitana de Belo Horizonte, concluindo que uma história de vida vinculada ao esporte foi a explicação mais formulada pelos gestores para justificar o caminho percorrido em direção à ocupação de cargos públicos vinculados ao esporte e ao lazer.

No caso de S8, é possível observar que sua realidade se assemelha apenas parcialmente ao cenário descrito por Linhares et al. (2008), haja vista que o passado esportivo desse profissional entrevistado não se deu como atleta profissional. Em contrapartida, sua vivência no esporte permeou seu cotidiano profissional e pode ser vista como influência em sua ocupação atual.

Diante disso, o vínculo com um passado esportivo é um dado relevante para se pensar a formação dos profissionais que atuam em políticas 
de esporte e lazer. Não pode ser considerado uma condição sine qua non, mas, após a análise do contexto pesquisado, ficou claro que se trata de elemento presente recorrentemente na vida dos sujeitos.

Todos os entrevistados tiveram seu ingresso na SMEL por concurso público como oportunidade profissional obtida após a conclusão da graduação em Educação Física. Elucidam que, inicialmente, o gosto pelas políticas públicas não se constituiu em fator relevante para suas escolhas, até porque essa foi uma área pouco abordada em sua formação. Notamos que os sujeitos acabam por entrar no setor público sem conhecê-lo e sem referências para atuação em políticas públicas.

A forma de ingresso foi através de concurso público, nunca tinha pensado na possibilidade de atuar no setor público e na época vi o edital e as descrições das atividades e me interessei a fazer o concurso, pois no edital estavam muito explícitas as atividades do analista de políticas públicas, que era trabalhar com a formulação, elaboração e coordenação de políticas públicas de esportes e lazer. Então, para diversificar a área de atuação, resolvi fazer o concurso (S1).

O ingresso dos analistas no setor público ocorreu sem que possuíssem base conceitual - elemento importante a ser analisado. Esse é um ponto que reforça os limites da formação em educação física para atuação no campo profissional, mas não deve ser o único eixo de análise para se pensar na intervenção. O início de qualquer trabalho envolve uma fase de sensibilização, que leva os sujeitos a conhecerem o ambiente e, aos poucos, suas particularidades. Nesse contexto, surgem perguntas e inquietações que, quando elucidadas, acabam por amadurecer e trazer segurança para a intervenção dos profissionais.

Silva e Silva (2012) afirmam que a formação profissional para atuação nas políticas públicas de esporte e lazer deve enfatizar o duplo aspecto educativo dessas: o de veículo de educação e o de objeto de educação. Sob o prisma que as revelam veículo de educação, devem-se considerar as potencialidades para o desenvolvimento pessoal e social dos indivíduos. $\mathrm{O}$ aspecto de objeto de educação implica a necessidade de difusão do significado dessas políticas públicas, esclarecendo sua importância e incentivando a participação dos sujeitos.

Assim, Silva e Silva (2012, p. 31) comentam que

o profissional de educação física, ao ter uma formação sólida nas ciências sociais e humanas, poderá ter mais condições de uma intervenção efetiva no âmbito do lazer no sentido de viabilizar aos sujeitos o acesso aos conteúdos clássicos, o enfrentamento das barreiras sociais no sentido de superá-las, a realização de ações com o intuito de atingirem os níveis crítico e criativo. Enfim, terá uma atuação que leve em conta a abrangência do lazer e sua especificidade, seja na escola, nos clubes, seja nas comunidades.

As falas dos sujeitos suscitam discussões acerca dos conhecimentos envolvidos na formação em educação física. Faria Junior (2003) destaca que os profissionais da área se encontram diante de problemáticas que 
não conseguem enfrentar em razão da sua formação especializada, que privilegia alguns conhecimentos em detrimento de outros.

Os currículos da educação física tendem a fracionar o conhecimento, centrando sua abordagem em elementos reconhecidamente específicos da área: motricidade, esporte, cultura do movimento, fitness. Para Taffarel (1993), esse contexto enfatiza um processo de formação acrítico, que ocorre sob o paradigma da aptidão física, com forte influência da área biológica. A autora aponta para a dicotomia entre teoria e prática, uma vez que os profissionais são preparados para atuar no mercado de trabalho por meio de uma intervenção centrada no fazer. No entanto, para que de fato seja possível intervir socialmente, é preciso que os sujeitos sejam estimulados a valorizar suas práticas de lazer e a pensá-las de forma crítica e reflexiva.

Nessa direção, Marcellino (2008) enfatiza que a educação para o lazer pode ser entendida como instrumento de defesa contra a homogeneização e internacionalização dos conteúdos veiculados pelos meios de comunicação de massa, atenuando seus efeitos, mediante o desenvolvimento do espírito crítico.

Mais uma vez deparamo-nos com a ideia de que o profissional é um ser cultural, permeado por diferentes tipos de experiências que contribuem para e influenciam sua formação como agente do lazer. A questão em foco relaciona-se com a organização de tais experiências e com a seleção, por parte dos profissionais, das experiências que reúnam elementos adequados para nortear as propostas de esporte e lazer sob sua responsabilidade.

Notamos, porém, uma tendência de preparação técnica dos profissionais de educação física, ao passo que há limites na construção de um conhecimento amplo, formado criticamente. Faria Junior (2003) propõe uma formação generalista, que suponha domínio de teorias que permitam ao profissional atuar em todos os campos de intervenção da área, inclusive nas políticas públicas. Para o autor, o conhecimento de teorias sociológicas, por exemplo, permite analisar o funcionamento da sociedade - a divisão de classes, os aspectos distributivos e relacionais entre elas, as políticas constituídas e seus princípios. Talvez, esse seja o caminho a ser percorrido para superar as dificuldades encontradas pelos profissionais quando ingressam no setor público.

Outro aspecto refere-se à contribuição das experiências profissionais dos sujeitos em sua formação. Observamos dois comportamentos distintos com relação às formas de entrada e permanência no mercado de trabalho. O primeiro é o dos profissionais que, apesar de passarem por outras áreas de atuação, concentraram toda sua vida profissional na Secretaria Municipal de Esporte e Lazer. Nesse caso, os sujeitos possuem experiências com docência, orientação de atividades físicas, esporte de rendimento, entre outras. Tais ocupações, porém, não se fizeram presentes por período superior a dois anos em suas vidas profissionais. Cinco sujeitos se enquadram nesse perfil: 
Fora da Secretaria eu trabalhei em escola estadual como professor concursado com carreira estadual e trabalhei tanto no ensino médio quanto no fundamental do Estado e também trabalhei em academias na área da musculação. Porém, há quase dez anos me dedico exclusivamente às atividades da SMEL (S7).

Já o segundo comportamento provém de profissionais que conciliam o trabalho na SMEL com outras atividades ligadas à educação física. Durante as entrevistas, percebemos que não se trata, somente, de uma opção por complementação financeira. Optam por esse caminho para não se afastarem de outros espaços de intervenção no mercado de trabalho ou de alguma área do conhecimento que proporciona maior reconhecimento e visibilidade. Nesse aspecto, é importante destacar o desejo de não se afastar do mercado - como se a própria atuação no âmbito das políticas públicas não pudesse ser considerada uma possibilidade dentro do mercado de trabalho.

\section{Saberes e competências: a visão de profissionais da SMEL}

Refletir sobre a formação de profissionais para atuação nas políticas de esporte e lazer nos remete à compreensão dos saberes, competências e habilidades necessárias à ação. Concordamos com Tardif (2000) em sua afirmação de que os conhecimentos profissionais exigem autonomia e discernimento, ou seja, não se constituem apenas em conhecimentos técnicos padronizados e codificados. Nessa direção, a formação deve conduzir o profissional a reflexões que o levem a compreender os problemas, organizá-los e buscar meios de atingir os objetivos almejados. O saber não é algo rígido, imutável, pois é também ferramenta de intervenção profissional que se desloca ao encontro das concepções e estratégias de cada sujeito.

Nesta pesquisa, investigamos os saberes que os sujeitos julgam importantes para sua atuação profissional, o que evidenciou o leque de possibilidades de atuação nas políticas públicas de esporte e lazer. Vale compreender que os saberes se traduzem no domínio de conhecimentos sobre determinado tema e nos conteúdos relacionados a ele. A utilização desses conteúdos na solução de problemas corresponde às competências profissionais.

A compreensão sobre os saberes pode diversificar as formas de intervir no campo, mas, em contrapartida, pode dificultar a definição de um eixo sobre os conhecimentos necessários para atuação. A entrevista de um dos sujeitos (S4) aponta para esse contexto de exigência de diversos conhecimentos que se complementam:

Primeiramente é preciso ter um conhecimento macro sobre lazer. Porque se a gente não tem esse conhecimento, deixamos de estar alertas para algumas situações e corremos o risco de cair em algumas ciladas que estão colocadas, como a cilada da indústria cultural e da esportivização do lazer. E preciso conhecer o lazer como um fenômeno moderno, assim como a gestão pública - até mesmo com a equipe que irá atuar na ponta. Também é preciso conhecer a área de atuação das demais secretarias, 
bem como estabelecer um diálogo aberto com elas. Saber os princípios da gestão pública, da intersetorialidade e da participação popular é importante para não sermos tratados como animadores de circo (S4).

Uma importante dimensão da atuação do profissional que atua no campo de lazer refere-se à animação cultural, entendida, segundo Melo (2006, p. 28),

\begin{abstract}
como uma tecnologia educacional - uma proposta de intervenção pedagógica - pautada na ideia radical de mediação, que busca permitir compreensões mais aprofundadas acerca dos sentidos e significados culturais que concedem concretude à nossa existência cotidiana, construída com base no princípio de estímulo às organizações comunitárias, sempre tendo em vista provocar questionamentos acerca da ordem social estabelecida e contribuir para a superação do status quo e para a construção de uma sociedade mais justa.
\end{abstract}

A partir dessa perspectiva, o desafio é criar condições para que todos possam ter acesso aos meios de produção cultural. Torna-se necessário, também, criar mecanismos para se garantirem fluxos culturais, encarando todos os envolvidos como potenciais produtores culturais, e não somente consumidores. O animador cultural deve compreender os processos de produção e consumo cultural da sociedade, sendo sua responsabilidade promover intervenções pedagógicas considerando o momento histórico vivido.

Marcellino (2011) afirma que o animador pode ter diferentes formações. São professores de educação física, arte-educadores, profissionais de turismo, hotelaria, entre outros que dominam um conteúdo cultural e desejam compartilhá-lo com outras pessoas. Para isso, é necessário ter uma sólida cultura geral que lhes possibilite perceber a ligação de seu conteúdo de domínio com os demais; exercer, cotidianamente, a reflexão e a valoração próprias à ação de educador, que os diferenciará dos mercadores da indústria cultural; e ter o compromisso político com a mudança da situação em que nos encontramos.

Considerando a diversidade cultural e social do Brasil, esse é o desafio a ser vencido pelos profissionais que irão elaborar, implementar, monitorar e avaliar as políticas públicas de esporte e lazer, uma vez que essas envolvem uma teia de conhecimentos para além da formação profissional específica da área. Consequentemente, o sujeito deve compreender seu papel formador e estabelecer estratégias para organizar os conhecimentos a fim de refletir acerca das possíveis formas de atuação que poderão garantir o alcance de seus objetivos.

Emergiu do contexto analisado a necessidade de conhecer as teorias ligadas à política e às políticas públicas, de modo mais específico, às questões da legislação e da gestão de serviços públicos. Dominar conteúdos específicos do esporte e do lazer também é necessário, uma vez que concebê-los de forma clara pode potencializar suas possibilidades de transformação da sociedade. 
Os conhecimentos ligados à gestão também se evidenciam nas falas dos sujeitos. Nesse sentido, a figura do profissional que atua como analista de políticas públicas de esporte e lazer não se enquadra somente em padrões técnicos ou executivos; relaciona-se também com a perspectiva gerencial, uma vez que organizam e atuam como gestores dos programas e ações de sua responsabilidade. Somada a isso, a fala do sujeito 4 (S4) mostra que há necessidade de se conhecer a realidade daqueles que trabalharão na ponta, sendo esse um ponto fundamental para a concepção de ações e programas pautados na realidade do campo de intervenção.

Percebemos que os saberes ligados à intervenção profissional nas políticas públicas de esporte e lazer se enquadram em quatro eixos principais: (a) os saberes específicos da área de intervenção das políticas, ou seja, da área do esporte e do lazer; (b) os saberes relacionados às políticas; (c) os saberes ligados à gestão; (d) os saberes que envolvem a prática profissional.

Por atuarem nas políticas de esporte e lazer, todos os sujeitos pesquisados mencionaram que é fundamental conhecer os conteúdos ligados especificamente ao esporte e ao lazer. Nessa perspectiva, é relevante para a intervenção desse profissional que ele tenha concepções bem definidas sobre as temáticas, o que irá auxiliá-los na solução dos problemas do dia a dia - como pode ser observado na declaração do sujeito 8 (S8):

\footnotetext{
Meu programa tem as duas coisas: lazer e esporte. Tem os meninos que vêm aqui para iniciar um processo de socialização junto à sociedade, mas já tem meninos que têm ótimos resultados nas competições. Eu preciso saber lidar com isso porque em alguns momentos as características de um e de outro se afastam. A cobrança de fazer uma técnica adequada no judô pode ser diferente numa mesma aula por aqui (S8).
}

É preciso ter em mente, porém, que existem diferentes concepções sobre esporte e lazer, que ora os aproxima, ora os distancia. Menicucci (2008) destaca que os conceitos sobre esporte e lazer podem conter ambiguidades e ser definidos de diferentes formas. Para a autora, esse é um fator que traz dificuldades para a definição do escopo de políticas voltadas para sua garantia como direitos.

O sujeito 4 (S4) reconhece que "os conceitos de esporte e lazer ainda se constatam como elementos em amadurecimento dentro da SMEL". Uma explicação para isso pode ser dada pela hipótese de que a inserção desses temas na agenda pública é recente (Linhales et al., 2008). Nesse sentido, ainda ocorre, no setor público, uma fase de assimilação dos entendimentos convergentes e divergentes presentes nas relações que se estabelecem entre esporte e lazer.

Lopes e Isayama (2011) buscaram compreender a atuação dos profissionais de lazer no setor público municipal e identificaram que seu dia a dia pode apresentar características que vão do fazer técnico ao fazer político. Nesse sentido, os profissionais atuam sob o viés gerencial, mas também sob uma perspectiva técnica, ou seja, em alguns casos, o contexto 
leva os profissionais que pensam as políticas ao papel de executores das atividades.

Apesar de o contexto analisado não apresentar, na maioria das vezes, essa demanda profissional dupla, as dificuldades enfrentadas cotidianamente no setor público podem levar os analistas a atuar tecnicamente. No trecho seguinte, um dos sujeitos pesquisados (S8) aborda sutilmente a questão e traz novos apontamentos sobre os conhecimentos necessários para a intervenção nas políticas:

Escrita de projetos é algo que eu gostaria de saber um pouco mais, além de gestão com base no relacionamento com pessoas. Pelo lugar que estou, acho que essa abordagem gerencial tem mais a ver com a função de analista - que em tese não tem que dar aula e trabalhar com treinamento, apesar de acontecer frequentemente (S8).

Nesse ponto, é possível inferir que os analistas de políticas públicas não devem limitar seus conhecimentos sobre esporte e lazer apenas pela vertente teórica. Quando chamados a atuar na execução das atividades propostas por seus programas, é preciso mobilizar os saberes relacionados ao fazer técnico, como ministrar aulas esportivas ou desenvolver atividades em uma rua de lazer. Esse processo também auxiliará os analistas a compreenderem a realidade e, consequentemente, as demandas dos profissionais de sua equipe que atuam na ponta.

Não se pode desejar, porém, que os analistas de políticas públicas dominem todos os conteúdos relacionados à sua intervenção profissional. Assim, os sujeitos arrolaram alguns saberes que faltam ou possuem deficiências, conhecimentos de que os profissionais da área sentem necessidade em seu dia a dia, conforme o trecho a seguir:

Acho que hoje preciso entender melhor o que são técnicas de preservação da memória, quais as suas finalidades. Como estou no início de um trabalho, acho interessante buscar esse conhecimento. Outra questão que sempre faz falta é o conhecimento de instrumentos de planejamento orçamentário no serviço público; ou seja: o que é e qual a finalidade de um $P P A G^{1}$. Sabemos que os recursos públicos são escassos, se não entendermos como funciona fica complicado (S1).

A fala desse sujeito mostra a necessidade de aprofundamento em conteúdos que se relacionam ao dia a dia de trabalho nos programas de sua responsabilidade, sendo mencionada a complementariedade de conhecimentos teóricos e técnicos. A fala do sujeito 1 (S1) elucida a necessidade de conhecer as técnicas de preservação da memória e de utilização das ferramentas gerenciais de governo, bem como a necessidade de conhecer as características peculiares das políticas públicas e de inserir o esporte e o lazer nesse contexto.

Esses saberes, quando concretizados em ações, se traduzem nas competências necessárias para a intervenção profissional no cotidiano. No que tange às competências gerenciais, os levantamentos obtidos na pesquisa assinalam a capacidade de se relacionar (com) e liderar pessoas,
O PPAG é o Plano Plurianual de Ação Governamental, que se constitui como instrumento legal normatizador no planejamento de médio prazo da esfera pública. Explica diretrizes, objetivos, programas, ações e metas a serem atingidos, definindo, quantitativamente, os recursos necessários para a sua implementação. É referência para a formulação dos programas de governo no período de quatro anos, atuando como importante ferramenta para se pensar o futuro. Com o PPAG, decidem-se quais serão os investimentos prioritários para os projetos de desenvolvimento da cidade. 
realizar feedbacks, formar e capacitar um quadro de profissionais, lidar com administração e alocação de recursos, escrever projetos, entre outras.

A análise a seguir busca contemplar os aspectos ligados à gestão no setor público, que possui diferentes características e, consequentemente, deverá ser abordada considerando algumas peculiaridades. Para tal, destacamos que os analistas de políticas públicas atuam como gestores dos programas pelos quais se responsabilizam, de modo que os conceitos relacionados à gestão pública se aplicam diretamente em sua intervenção profissional.

Azevedo e Barros (2004) apontam que a profissionalização da gestão pública deve passar pela formação integral dos gestores nos aspectos administrativos, tornando-se fundamental para a promoção do esporte e do lazer como direitos sociais. Os resultados podem ser observados quando ocorre uma competente utilização dos recursos humanos e financeiros para a consecução dos objetivos sociais vinculados a esses direitos.

Nesse sentido, é preciso tratar da capacidade administrativa dos gestores públicos, a qual:

\begin{abstract}
vista como competência, está ligada à ação, envolve conhecimentos, capacidades, habilidades e condutas [...] que possibilitam a obtenção de resultados mediante planejamento, formulação, organização, implementação, avaliação e reajuste de planos de desenvolvimento, em todos os níveis [da política]. Dessa forma, essa capacidade, ou melhor, competência, [...] converte-se em recurso estratégico de modernização e desenvolvimento. No entanto, em países latino-americanos e, em especial no Brasil, existe uma lacuna entre esta capacidade e as responsabilidades crescentes que os Estados têm demandado nas últimas décadas. (Souza, 2002, p. 78).
\end{abstract}

Torna-se relevante destacar que essa capacidade administrativa se traduz nas competências inerentes à atuação dos profissionais nas políticas de esporte e lazer, de modo que o desenvolvimento dessas competências deve ser enfatizado nos processos formais de capacitação e absorvido na vivência da coisa pública, nas relações e experiências cotidianas. Assim, o profissional encontra-se em constante formação:

Tenho que assumir que estamos em constante formação, nunca estamos no ponto, mesmo quando se investe na formação acadêmica para além da graduação. Acredito que sempre podemos nos qualificar mais. Pensando minha vida prática aliada aos conhecimentos que busquei, acho que hoje tenho clareza de quais são os conhecimentos necessários para qualificar minha atuação na SMEL (S2).

Marcellino et al. (2007) afirmam que o mundo atual impõe ao gestor público o desafio de desenvolver programas de esporte e lazer baseados em iniciativas consistentes para atender às expectativas da sociedade, por meio de uma ação qualificada, que tenha origem no princípio de maior socialização e democratização dos bens culturais da humanidade.

Esse processo encontra algumas barreiras a serem superadas, como a formação dos gestores da área. Marcellino et al. (2007) destacam que esse fato fica evidente no cotidiano, quando se observam problemas 
na capacidade técnica dos gestores, entre os quais a ausência de formação continuada, a não utilização de profissionais capacitados, a falta de participação popular na elaboração de programas, o não acompanhamento das ações e outros.

Nesse sentido, gerenciar o esporte e o lazer no setor público caracteriza-se como um fenômeno sinérgico em que o sujeito deve ser capaz de planejar, organizar, dirigir e controlar as atividades próprias e as de outras pessoas, para atingir ou superar objetivos previamente definidos.

\section{Considerações finais}

Os dados nos auxiliaram a compreender que os profissionais que atuam com políticas públicas nas áreas de esporte e lazer mobilizam quatro eixos de saberes complementares: os saberes específicos da área de atuação; os conhecimentos sobre o contexto e os sujeitos da ação; os conhecimentos sobre política e políticas públicas; e o domínio de conteúdos relacionados à gestão.

O primeiro eixo refere-se aos saberes específicos da área de intervenção, neste caso, ao esporte e ao lazer. O saber sobre essas temáticas é considerado fundamental para a execução de políticas na área, o que pode significar a necessidade da formação em educação física para atuar, principalmente, no cargo de analista de políticas públicas de esporte e lazer. Isso porque a educação física é tida como uma das áreas do conhecimento que se aproxima dessas temáticas, apesar do destaque conferido ao lazer como campo multidisciplinar.

Além dos saberes específicos no campo do esporte e lazer, um segundo eixo de saberes é consolidado, uma vez que os profissionais devem compreender as características dos grupos que serão atendidos por seus programas e ações, levando em conta as dimensões biológicas e sociais dos sujeitos. Esse é um fator que pode aproximar as políticas das demandas da sociedade.

Por atuarem no setor público, o terceiro eixo a ser aprendido pelos sujeitos se relaciona com as políticas e as políticas públicas. Para atuar, é preciso conhecer teorias políticas, legislação, processos de formação de agenda, elaboração, implementação, execução, monitoramento e avaliação de políticas públicas. Vale ressaltar que esses saberes nem sempre são tratados na formação em educação física, o que demandou dos sujeitos de pesquisa uma busca para realização de diferentes ações de formação específicas no campo da política pública e/ou gestão pública.

O quarto eixo de saberes se relaciona a aspectos ligados à gestão, uma vez que esses profissionais que atuam em políticas públicas são gestores das ações sob sua responsabilidade. Com isso, destacamos que devem fazer parte da sua rotina elementos como gestão de pessoas, gestão de finanças, estratégia, liderança, elaboração e gestão de projetos. 
Por fim, os resultados da pesquisa demonstram a necessidade de formulação de propostas curriculares que possam redimensionar e ampliar o debate sobre a temática das políticas públicas de esporte e lazer, no contexto do curso de graduação em Educação Física. Além disso, apontam a necessidade de se valorizar a formação continuada, tanto na universidade quanto no próprio espaço de intervenção, por meio da participação em cursos de aperfeiçoamento, pós-graduação, eventos técnicos e científicos, bem como em ações ligadas à leitura da produção sobre o tema, como reuniões e grupos de estudo e trabalho, entre outras possibilidades. Trata-se, portanto, de um processo incessante, que objetiva a qualificação das ações que consolidam o esporte e o lazer na agenda política.

\section{Referências bibliográficas}

AZEVEDO, P. H.; BARROS, J. F. O nível de participação do Estado na gestão do esporte brasileiro como fator de inclusão social de pessoas portadoras de deficiência. Revista Brasileira Ciência \& Movimento, Brasília, v. 12, n. 1, p. 77-84, 2004.

BAGRICHEVSKY, M. A formação profissional em educação física enseja perspectivas (críticas) para atuação na saúde coletiva? In: FRAGA, A. B.; WACHS, F. (Org.). Educação física e saúde coletiva: políticas de formação e perspectivas de intervenção. Porto Alegre: Ed. da UFRGS, 2007. p. 33-45.

BARDIN, L. Análise de conteúdo. Lisboa: Edições 70, 1977.

BRASIL. Constituição (1988). Constituição da República Federativa do Brasil. Brasília, 1988. Atualizada até 20 set. 2007.

DAOLIO, J. Educação física escolar: em busca da pluralidade. Revista Paulista de Educação Física, São Paulo, v. 10, supl. 2, p. 40-42, 1996.

FARIA JUNIOR, A. G. Perspectivas na formação profissional em educação física. In: MOREIRA, W. W. (Org.). Educação física \& esportes: perspectivas para o século XXI. 11. ed. Campinas: Papirus, 2003. p. 227238.

GOMES, C. L. Lazer: necessidade humana e dimensão da cultura. Revista Brasileira de Estudos do Lazer, Belo Horizonte, v. 1, n. 1, p. 3-20, jan./ abr. 2014.

ISAYAMA, H. F. Recreação e lazer como integrantes de currículos dos cursos de graduação em educação física. 2002. 197 f. Tese (Doutorado em Educação Física) - Faculdade de Educação Física, Universidade Estadual de Campinas, Campinas, 2002. 
ISAYAMA, H. F. et al. Lazer, políticas públicas e formação profissional: análise da política de formação profissional de secretarias de esporte de municípios da região metropolitana de Belo Horizonte. In: ISAYAMA, H. F. (Org.). Gestão de políticas de esporte e lazer. Belo Horizonte: Ed. da UFMG, 2011. p. 211-227.

ISAYAMA, H. F.; LINHALES, M. A. Avaliação de políticas e políticas de avaliação: questões para o esporte e o lazer. Belo Horizonte:

Ed. da UFMG, 2008.

KOGUT, M. C.; MARTINS, P. L. O. Os saberes iniciais dos acadêmicos de educação física. In: CONGRESSO NACIONAL DE EDUCAÇÃO EDUCERE, 9., 2009, Curitiba. Anais... Curitiba: PUCPR, 2009. Disponível em: <http://www.pucpr.br/eventos/educere/educere2009/anais/ pdf/3001_2007.pdf $>$.

LINHALES, M. A. et. al. Esporte e lazer na Grande BH: por onde caminham as gestões públicas? In: ISAYAMA, H. F.; LINHALES, M. A. Avaliação de políticas e políticas de avaliação: questões para o esporte e o lazer. Belo Horizonte: Ed. da UFMG, 2008. p. 13-58.

LOPES, T. B.; ISAYAMA, H. F. Sobre o fazer técnico e o fazer político: a atuação do profissional de lazer no serviço público municipal. Revista Brasileira de Ciência \& Movimento, Brasília, v. 19, n. 1, p. 87-99, 2011.

MARCELlinO, N. C. (Org.). Políticas públicas setoriais de lazer: o papel das prefeituras. Campinas: Autores Associados, 1996. (Coleção Educação Física e Esportes).

MARCELLINO, N. C. Lazer e esporte: políticas públicas. Campinas: Autores Associados, 2001.

MARCELLINO, N. C. et al. Políticas públicas de lazer: formação e desenvolvimento de pessoal: os casos de Campinas e Piracicaba - SP. Curitiba: Opus, 2007.

MARCELLINO, N. C. (Org.). Lazer e sociedade: múltiplas relações. Campinas: Alínea, 2008.

MARCELLINO, N. C. (Org.). Sistema nacional de esporte e lazer. Brasília: Gráfica e Editora Ideal, 2011. (Cadernos interativos: elementos para o desenvolvimento de políticas, programas e projetos intersetoriais, enfatizando a relação lazer, escola e processo educativo, 3).

MELO, V. A. A animação cultural: conceitos e propostas. Campinas: Papirus, 2006.

MENICUCCI, T. Políticas de esporte e lazer: o estado da arte e um objeto em construção. In: ISAYAMA, H. F.; LINHALES, M. A. Avaliação de políticas e políticas de avaliação: questões para o esporte e o lazer. Belo Horizonte: Ed. da UFMG, 2008. p. 179-202. 
PINTO, L. M. S. M. et al. Desafios para a gestão das políticas de lazer no Brasil. In: ISAYAMA, H. F. et al. (Org.). Gestão de políticas

de esporte e lazer: experiências, inovações, potencialidades e desafios. Belo Horizonte: Ed. da UFMG, 2011. p. 27-50.

SCHÖ, D. Educando o profissional reflexivo: um novo design para o ensino e aprendizagem. Porto Alegre: Artmed, 2007.

SILVA, C. L.; SILVA, T. P. Lazer e educação física: textos didáticos para a formação de profissionais do lazer. Campinas: Papirus, 2012.

SOUZA, E. C. L. A capacitação administrativa e a formação de gestores governamentais. Revista de Administração Pública, Rio de Janeiro, v. 36, n. 1, p. 73-88, jan./fev. 2002 .

STOPPA, E. A. et al. (Org.). Gestão de esporte e lazer. São Paulo: Plêiade, 2011.

SUASSUNA, D.; ALMEIDA, A. Políticas públicas para o esporte e o lazer no Brasil. In: ENCONTRO DA ASSOCIACÃO NACIONAL DE PÓS-GRADUACÃO E PESQUISA EM CIENCIAS SOCIAIS, 30., 2005, Caxambu. Anais... Caxambu: ANPOCS, 2005.

TAFFAREL, C. N. Z. A formação do profissional da educação: o processo de trabalho pedagógico e o trato com o conhecimento no curso de educação física. 1993. 230 f. Tese (Doutorado em Educação) Faculdade de Educação, Universidade Estadual de Campinas, Campinas, 1993.

TARDIF, M. Saberes profissionais dos professores e conhecimentos universitários: elementos para uma epistemologia da prática profissional dos professores e suas consequências em relação à formação para o magistério. Revista Brasileira de Educação, Rio de Janeiro, n. 13, p. 5-24, jan./abr. 2000.

TARDIF, M. Saberes docentes e formação profissional. 9. ed. Petrópolis: Vozes, 2008.

VAZ, A. F. Políticas públicas para o esporte e o lazer em Santa Catarina: reflexões e considerações. Revista da Educação Física/UEM, Maringá, v. 12, n. 1, p. 89-96, 1. sem. 2001.

Recebido em 16 de julho de 2016.

Solicitação de correções em 17 de novembro de 2016.

Aprovado em 30 de novembro de 2016. 